File 2792, 43(4) 2nd Print (7)

Avaiable online at www.banglajol.info

Bangladesh J. Sci. Ind. Res. 43(4), 501-512, 2008
BANGLADESH JOURNAL OF SCIENTIFIC AND INDUSTRIAL RESEARCH

E-mail: bjsir07gmail.com

\title{
Synthesis of Ca-hydroxyapatite Bioceramic from Egg Shell and its Characterization
}

\author{
Samina Ahmed*a and Mainul Ahsan ${ }^{\mathrm{a}}$ \\ Institute of Glass and Ceramic Research and Testing, Bangladesh Council of Scientific and \\ Industrial Research (BCSIR), Dr. Quadrat-i-Khuda Road, Dhanmondi, Dhaka - 1205, \\ Bangladesh
}

\begin{abstract}
Ca-hydroxyapatite (HA) was synthesised from egg shell under different conditions and characterised by using AAS, FT-IR, XRD, SEM and EDS techniques. The results of these analyses combined together indicate that sintered HA sample1 resembles the feature of pure and single apatite phase having hexagonal structure. A Ca/P molar ratio of 1.69 was achieved in this case. On the other hand HA obtained from calcined egg shell is a combination of both amorphous and crystalline phase and revealed a sub-stoichiometric Ca-deficient apatite form with a Ca/P ratio of 1.50 .
\end{abstract}

Keywords: Ca-hydroxyapatite, Biomaterials, Hexagonal, stoichiometric apatite, Ca-deficient apatite

\section{Introduction}

Recently, applications of bioceramic materials in biomedical fields has received considerable attention (Feng et al. 2005, Xu et al. 2001, Balázsi et al. 2007, Sasikumar et al. 2006) and researchers are now actively engaged in developing many routes to synthesis Ca-phosphate based bioceramic materials using different sources of calcium (Ca) and phosphate (P) (Feng et al.2005, Xu et al. 2001, Balázsi et al. 2007, Sasikumar et al. 2006). Bioceramics are required to alleviate pain and restore function of diseased and damaged body parts. Ca-phosphate based synthetic ceramic materials, particularly, Cahydroxyapatite (HA), $\beta$-tricalcium phosphate $(\beta$-TCP) and their composites are extensively used for medical purposes that includes tissue engineering, implants, coating on prostheses and bone filling materials (Prabakaran et al. 2005). However, among these bioceramics, $\mathrm{HA}, \mathrm{Ca}_{10}\left(\mathrm{PO}_{4}\right)_{6}(\mathrm{OH})_{4}$, is an important inorganic material in both biology and chemistry (Markovic et al. 2004) and due to its excellent bioactive, biocompatible nature and bone bonding ability with surrounding tissues it is widely used in tissue

* Correspondence author, E-mail: bcsir@yahoo.com,ahsan1953@yahoo.com 
engineering and bone replacement (Balázsi et al. 2007). It is well known that human bone is a hybrid composition of inorganic ( 70\% apatitic calcium phosphate with a $\mathrm{Ca} / \mathrm{P}$ ratio 1.66$)$ and organic ( 30\% collagen) materials. The demands for synthetic HA as a substitute material for bone and teeth in orthopedic and dentistry fields are increasing day by day. Considering the numerous applications of HA in biomedical fields, development of various synthesis methods is a major issue now and obviously, a simple cost-effective procedure is highly desirable to the researchers. A number of synthesis techniques using various sources of $\mathrm{Ca}$ and $\mathrm{P}$ have been developed which includes wet chemical method (precipitation), sol-gel method, hydrothermal synthesis procedure, continuous precipitation, thermal deposition and solid state reaction method (Feng et al. 2005, Balázsi et al. 2007, Thamaraiselvi et al. 2006). However, among these methods, wet chemical precipitation route is popular because of its simple, cheap and easy application in industrial production.

Although the demand of wet precipitation method scores high, the choice of raw materials to use as $\mathrm{Ca}$ and $\mathrm{P}$ precursors is the key factor in any method to be developed. From this point of view, in this work we have adapted wet chemical method to synthesize pure HA bioceramics with $\mathrm{Ca} / \mathrm{P}$ ratio 1.66 , using egg shell as Ca source. Depending on feeding egg shell contains about (94 - 97) \%
$\mathrm{CaCO}_{3}$ while rest of the percentage is organic matter and egg pigment. Egg shell is a waste material after the usage of egg. Hence, utilisation of egg shell will benefit in two ways: (i) egg shell derivated HA will be costeffective bioceramic material for biomedical applications, and (ii) utilisation of egg shell will be an effective material-recycling technology for waste management.

\section{Materials and Methods}

\section{Synthesis of HA}

At first the raw egg shells were cleaned thoroughly with water followed by boiling for $1 / 2$ hr. It was then dried overnight at $110^{\circ} \mathrm{C}$ in an oven and then crushed and powdered using an agate mortar. This egg shell powder was then divided into two portions: one portion remained uncalcined and percentage of $\mathrm{CaCO}_{3}$ ( 94\%) was determined via titration method, while the 2 nd portion was calcined at $950^{\circ} \mathrm{C}$ to burn out the organic and other substances. Both the uncalcined and calcined egg shell powder was used to synthesize HA according to the following procedure.

A stoichiometric amount of egg shell powder (both uncalcined and calcined) was dissolved in conc. $\mathrm{HNO}_{3}$ and $15 \mathrm{~mL}$ of distilled water was added to the acidic egg shell solution and filtered to get clear solution. Final volume was made up to $50 \mathrm{~mL}$ with distilled water and the $\mathrm{pH}$ of the solution was increased to $\sim 10.0$ with aqueous ammonia. A requisite amount of $0.10 \mathrm{M} \mathrm{Na}_{2} \mathrm{HPO}_{4}$. $12 \mathrm{H}_{2} \mathrm{O}$ in ammonia solution $(\mathrm{pH} \sim 10.0)$ was 
added drop wise to the egg shell solution with continuous stirring condition. White gelatinous precipitate of HA was formed which was stirred for overnight in the mother solution for ripening. The precipitate was filtered through a Buchner funnel and thoroughly washed with plenty of distilled water. At this stage, the filtered precipitate was dried at $110^{\circ} \mathrm{C}$ to remove any trace of water. The HA (sample 1) synthesised from uncal- cined egg shell was then subjected to calcination at $900^{\circ} \mathrm{C}$ for $1 / 2 \mathrm{hr}$, while the HA (sample 2) obtained from calcined egg shell remained as received, i.e. no further calcination was done, but crushed to achieve fine powder. A flow diagram of the synthetic procedure is given in Figure 1.

All the chemicals used for this study were Analar grade either from E. Merck or BDH

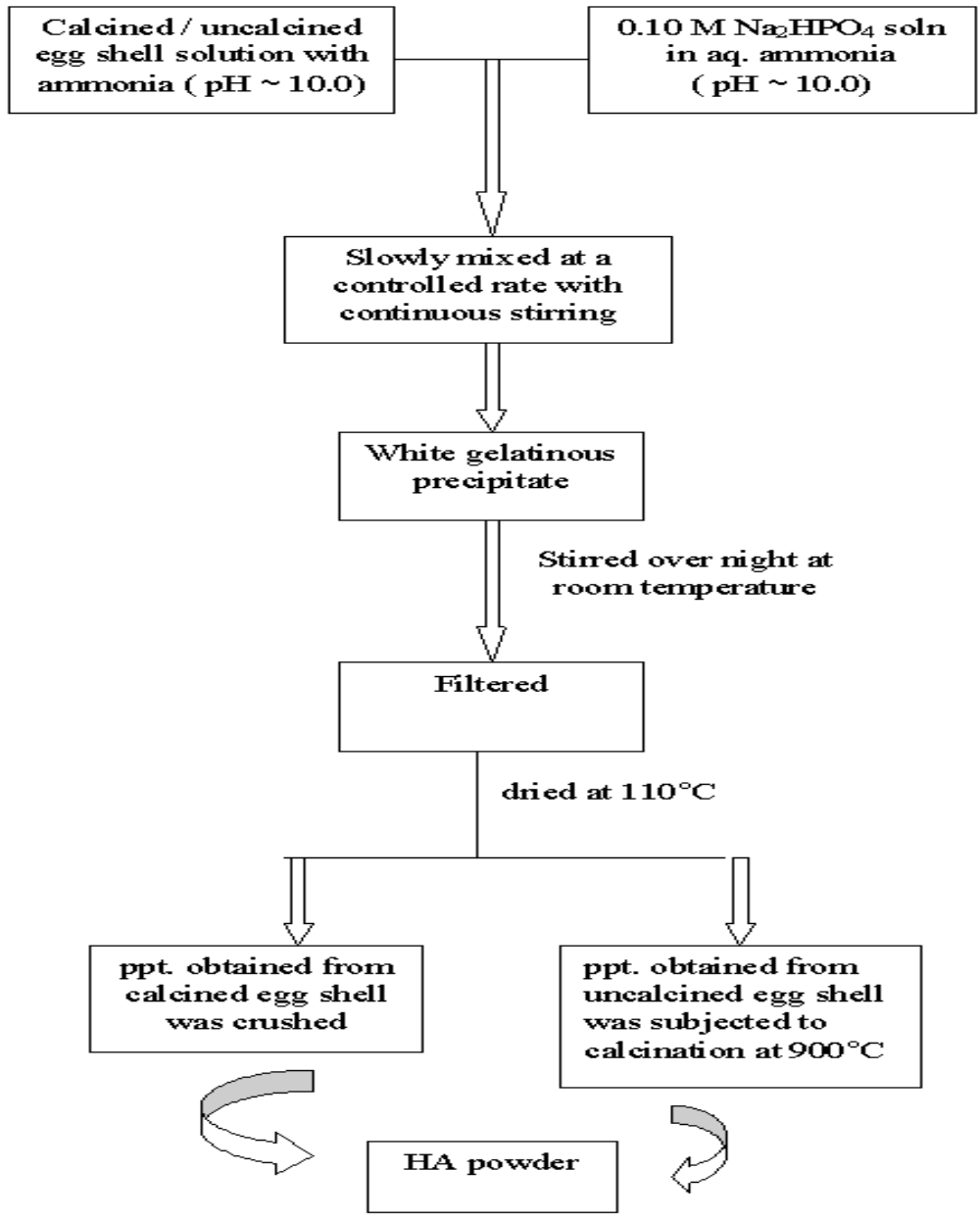

Fig. 1. Flow diagram of hydroxyapatite synthesis procedure from egg shell 
and the solutions were prepared using double distilled water.

\section{Characterisation of synthesised HA powders}

The semi quantitative elemental information of the samples was achieved by energy dispersive spectroscopy (EDS) as a preliminary technique. Then chemical analysis was done to determine the percentage of $\mathrm{Ca}$ and $\mathrm{P}$ by atomic absorption (AAS) and UV spectrophotometric methods respectively. Fourier transform infrared spectroscopy (FTIR, Model no. FT-IR - 8900, SHIMADZU) was used to identify the functional groups. Experimental spectra were obtained by using $\mathrm{KBr}$ disks with a 1:100 "samples-to-KBr" ratio and the samples were scanned in the wave number range of $4000 \mathrm{~cm}^{-1}-400 \mathrm{~cm}^{-1}$ with an average of 30 scans. The resolution of the spectrometer was $4 \mathrm{~cm}^{-1}$. Phase purity of the synthesised samples was examined by using PANalytical (X'Pert PRO XRD PW 3040). The intensity data were collected in $0.02^{\mathrm{O}}$ steps following the scanning range of $2 \theta=20^{\circ}-80^{\circ}$ using CuKa $\left(\gamma=1.54178^{\circ} \mathrm{A}\right)$ radiation. The phases developed in both the samples were compared and confirmed using standard JCPDS files (card no. 896439). The surface morphology and microstructural features of the samples were observed by Hitachi, S-3400N scanning electron microscopy (SEM) equipped with energy dispersive spectroscopy (EDS).

\section{Results and Discussion}

The EDS spectra of HA samples are shown in Figures $2 \mathrm{a}$ and $2 \mathrm{~b}$ respectively. The EDS spectrum of HA (sample 2) clearly shows the peaks of $\mathrm{Ca}, \mathrm{P}, \mathrm{C}$ and $\mathrm{O}$ as expected. The presence of $\mathrm{C}$ is quite usual in this case as the sample is only oven dried at $110^{\circ} \mathrm{C}$, whereas in case of HA sample $\mathbf{1}$ which was calcined at $900^{\circ} \mathrm{C}$, there is no trace of $\mathrm{C}$. This observation was further validated by FT-IR and XRD results. The $\mathrm{Ca} / \mathrm{P}$ molar ratio (1.74 and 1.499 for sample $\mathbf{1}$ and 2 respectively) was qualitatively calculated using EDS data. However, the chemical assessment provided quantitative information regarding the $\mathrm{Ca} / \mathrm{P}$ molar ratio of the HA samples. A ratio of 1.69 confirmed the stoichiometric nature of HA sample $\mathbf{1}$ whereas $\mathrm{Ca} / \mathrm{P}$ molar ratio of 1.50 showed the sample 2 as sub-stoichiometric calcium deficient HA.

The FT-IR spectra of the HA samples are shown in Figures 3a and 3b. The band positions and their respective assignments are given in Table I. The IR spectra of both the HA samples (1 and 2) exhibited well-defined absorption bands in the range of $962 \sim 1040$ $\mathrm{cm}^{-1}$ and $565 \sim 635 \mathrm{~cm}^{-1}$, characteristic of a well- crystallized apatite phase (Xu et al. 2001). The peaks appeared at $1039.6 \mathrm{~cm}^{-1}$ (HA sample 1) and $1035.7 \mathrm{~cm}^{-1}$ (HA sample 2) are assigned to asymmetric stretching vibration $\left(v_{3}\right)$ of $\mathrm{PO}_{4}{ }^{3-}$ groups, while the peaks at $962.4 \mathrm{~cm}^{-1}$ corresponds to the sym- 


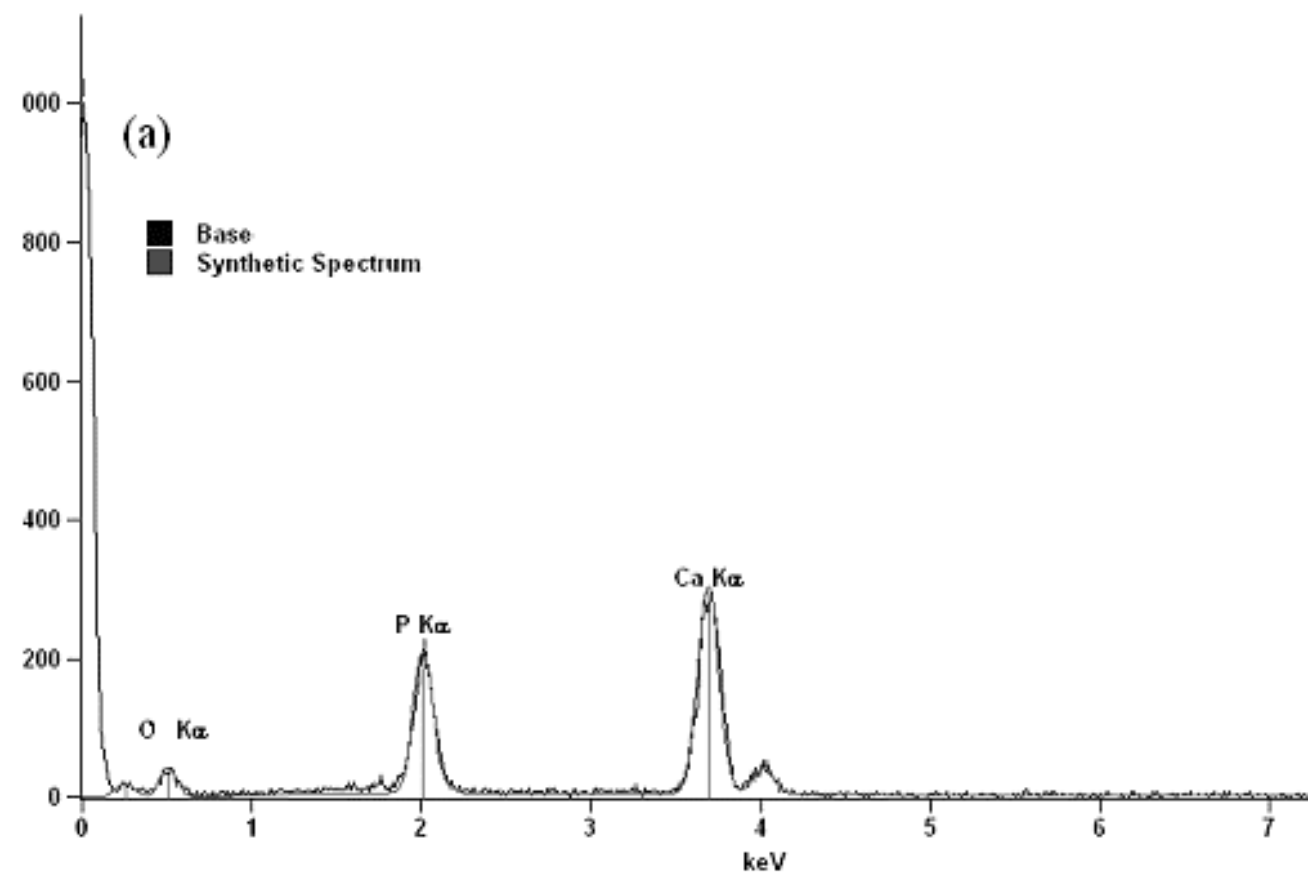

(b)

BaseHA

Synthetic Spectrum

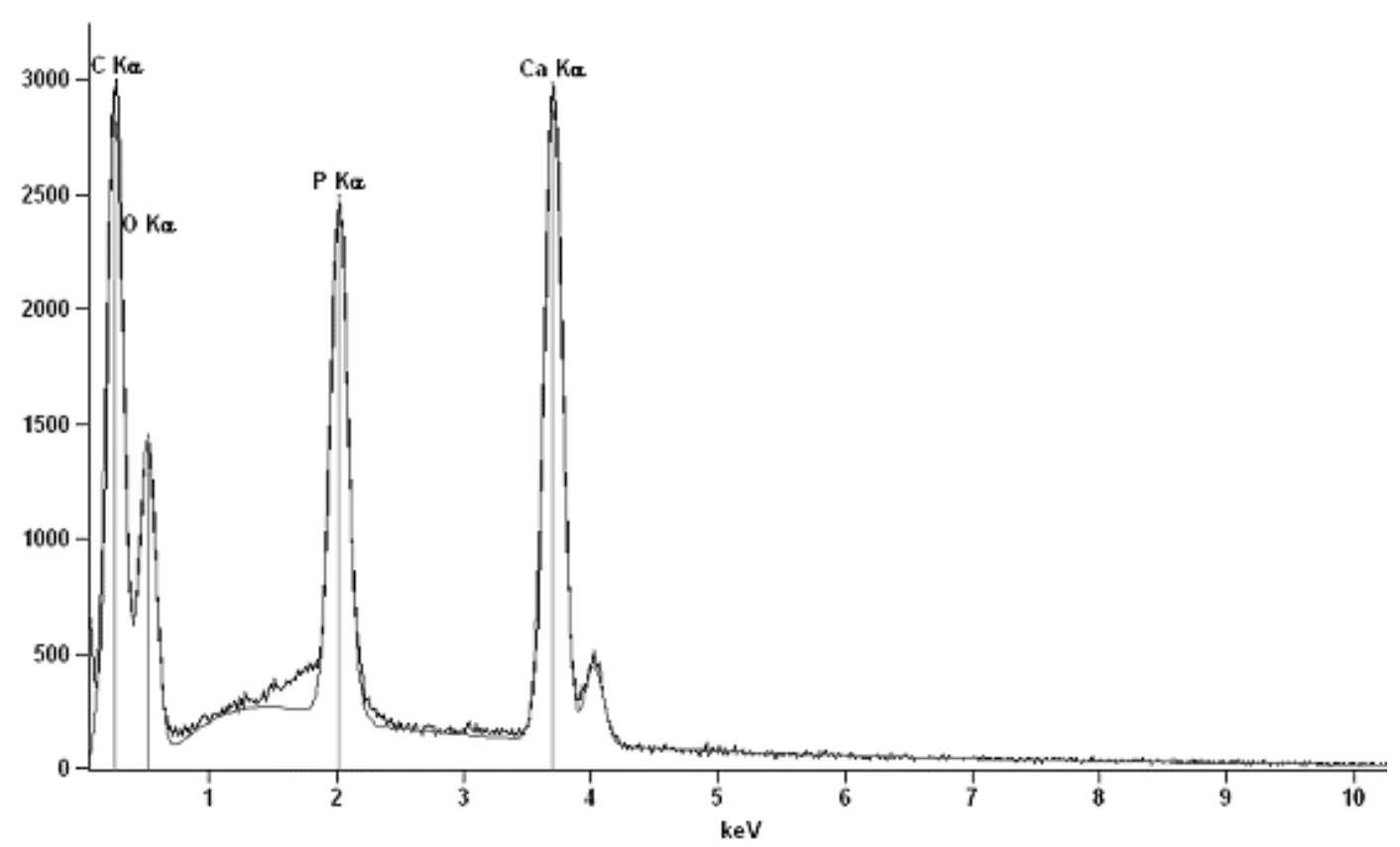

Fig. 2. EDS spectra of synthesised HA (a) HA sample 1 (b) HA sample 2. 

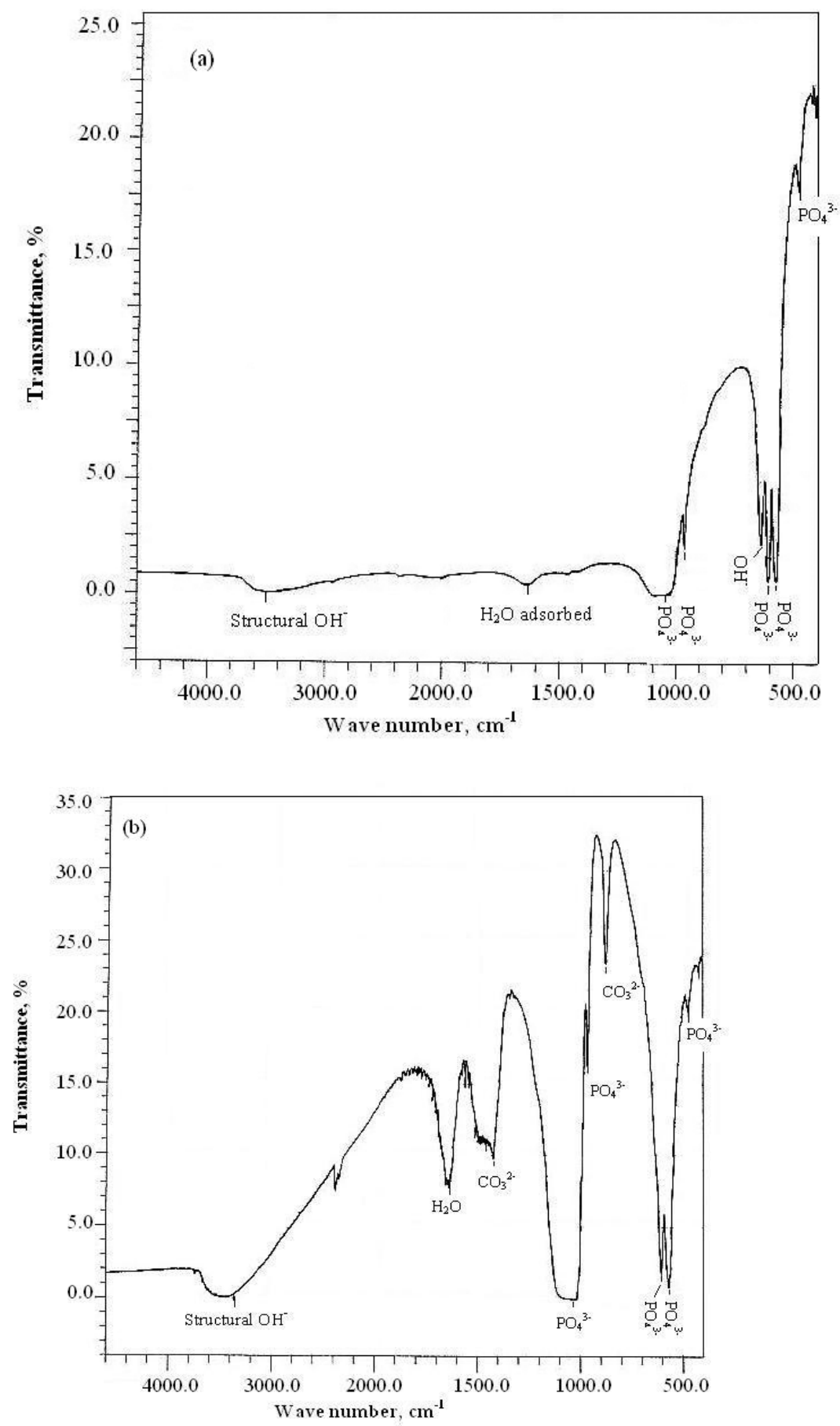

Fig. 3. FT-IR spectra of synthesised HA (a) HA sample 1 (b) HA sample 2. 
Table I : FT-IR band positions and their corresponding assignments

\begin{tabular}{c|c|l}
\hline \multicolumn{2}{c|}{ Observed band positions $\left(\mathrm{cm}^{-1}\right)$} & \multicolumn{1}{|c}{ Corresponding assignments } \\
\cline { 1 - 2 } HA sample 1 & HA sample 2 & \multicolumn{1}{|c}{} \\
\hline 474.5 & 472.5 & $\mathrm{PO}_{4}{ }^{3-}$ bending $\left(v^{2}\right)$ \\
570.9 & 565.1 & $\mathrm{PO}_{4}{ }^{3-}$ bending $\left(v^{4}\right)$ \\
601.7 & 603.7 & $\mathrm{PO}_{4}{ }^{3-}$ bending $\left(v^{4}\right)$ \\
632.6 & ---- & $\mathrm{OH}_{\text {liberation }(\text { Structural OH- })}$ \\
---- & 873.7 & $\mathrm{CO}_{3}{ }^{2-}$ group \\
962.4 & 962.4 & $\mathrm{PO}_{4}{ }^{3-}$ stretching $\left(v^{1}\right)$ \\
1039.6 & 1035.7 & $\mathrm{PO}_{4}{ }^{3-}$ bending $\left(v^{3}\right)$ \\
--- & 1419.5 & $\mathrm{CO}_{3}{ }^{2-}$ group $\left(v^{3}\right)$ \\
1650.0 & 1635.5 & $\mathrm{H}_{2} \mathrm{O}$ adsorbed $\left(v^{2}\right)$ \\
3500.0 & 3361.7 & Structural OH- \\
\hline
\end{tabular}

metric stretching $\left(v_{1}\right)$ mode of $\mathrm{PO}_{4}^{3-}$. Bending $\left(v_{3}\right)$ mode of $\mathrm{PO}_{4}{ }^{3-}$ group is observed at positions $474.5 \mathrm{~cm}^{-1}$ and 472.5 $\mathrm{cm}^{-1}$ for samples 1 and 2 respectively (Tas 2000). The sharp and peaks at 601.7 and $570.9 \mathrm{~cm}^{-1}$ for sample 1 and 603.7 and 565.1 $\mathrm{cm}^{-1}$ for sample 2 are assigned to the bending mode of $\mathrm{PO}_{4}^{3-}$. The noticeable large separation of these two bands further suggests the presence of crytallized apatitic phase (LeGeros 1991, Tas 2000). The IR spectra of the HA sample 2 (Fig. 3b) resembles the nature of hydrated carbonated apatite. The absorption bands observed in the region $1419.5 \mathrm{~cm}^{-1}$ and $873.7 \mathrm{~cm}^{-1}$ are due to the vibrational mode of $\mathrm{CO}_{3}{ }^{2-}$ group associated in amorphous phase (Xu et al. 2001). This observation is consistent with the $\mathrm{XRD}$ results. However, in case of calcined HA (Sample 1, calcined at $900^{\circ} \mathrm{C}$ ), there is no noticeable bands for $\mathrm{CO}_{3}{ }^{2-}$ group (Fig. 3a) indicating the elimination of $\mathrm{CO}_{3}{ }^{2-}$ due to the release of volatile gas. This sample also shows a sharp band at $632.6 \mathrm{~cm}^{-1}$, which is indicative of the presence of structural $\mathrm{OH}$ (OH liberation mode), whereas in the IR spectrum of HA sample 2 , the same band is not visible. This result attributed to the formation of good crystallinity for the HA sample $\mathbf{1}$ after calcination at $900^{\circ} \mathrm{C}$ which is also evidenced from the corresponding XRD data (Fig. 4a). The bands observed at $1635.5 \mathrm{~cm}^{-}$ 1 and $3361.7 \mathrm{~cm}^{-1}$ in HA sample 2 confirms the presence of adsorbed $\mathrm{H}_{2} \mathrm{O}$ which is quite usual since this sample remains in uncalcined state. On the other hand in case of sample $\mathbf{1}$, these bands are very weak indicating the loss of $\mathrm{H}_{2} \mathrm{O}$ molecules during calcination, but the additional band at $3500 \mathrm{~cm}^{-1}$ clearly represents the hydroxyl stretching mode associated with surface $\mathrm{P}-\mathrm{OH}$ groups (Mahabole et al. 2005). 


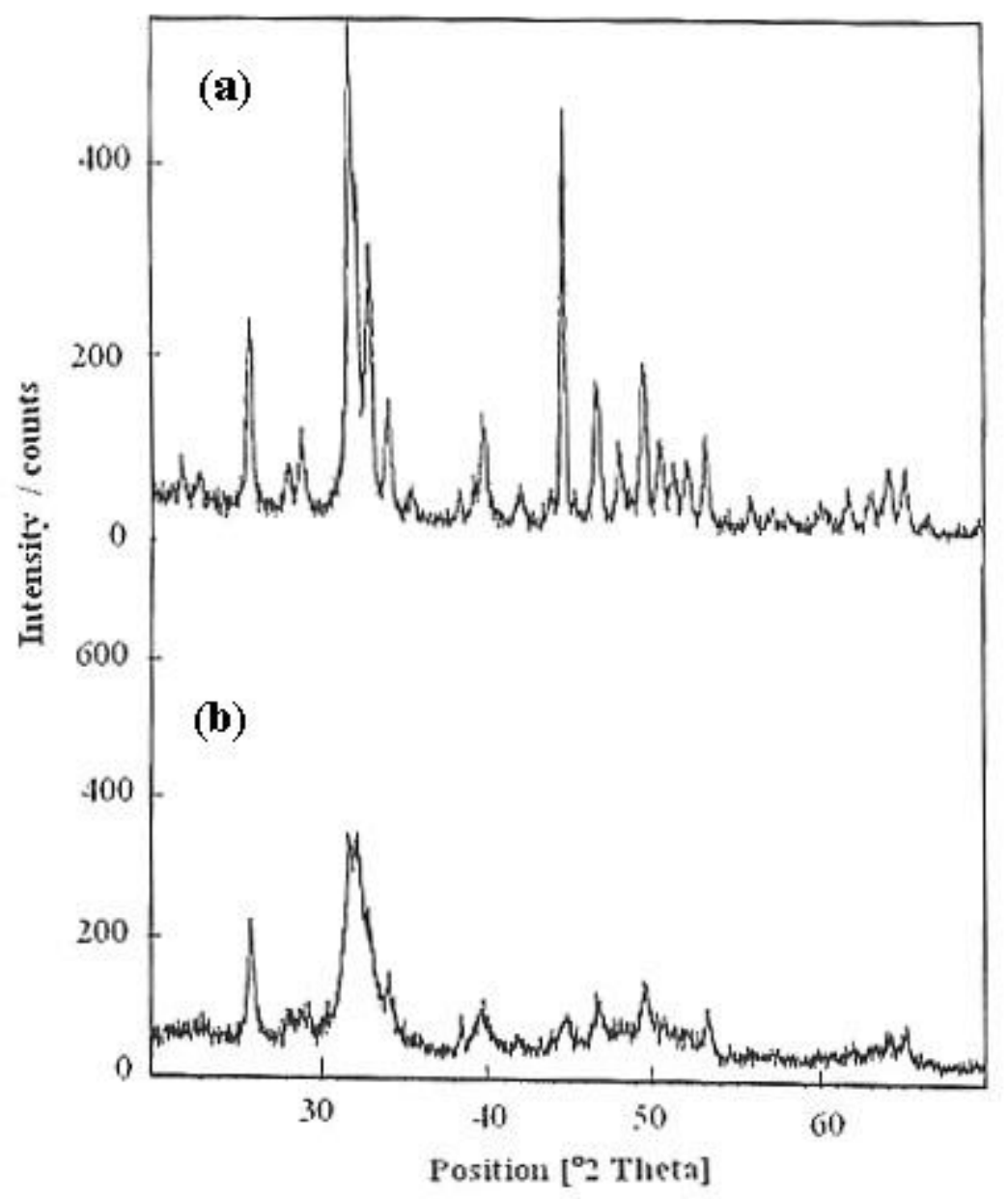

Figure 4. XRD spectra of synthesised HA (a) HA sample 1 (b) HA sample 2.

A typical XRD diffraction of sample $\mathbf{1}$ is presented in Figure 4a. The major $d$ spacing values are compared with the JCPDS standard data (Ref. code: 89-6439) for HAP and are summarized in Table II. A good agreement between the experimental data (achieved for sample 1) and JCPDS standard for calcium hydroxyapatite (Ref. code: 89-6439) both in terms of intensity and $d$-spacings (Table II) was obtained. Particularly the strong diffrac- tion peaks corresponding for hydroxyapatite at $2 \theta$ position $31.7858^{\circ}$ (211) plane together with other two peaks at $32.2665^{\circ}$ and $32.9515^{\circ}$ of almost equal intensities confirmed the formation of pure hydroxyapatite in crystallite form [19]. However no peak was detected at $29.399^{\circ}$ for calcium carbonate with HA phase (Vijayalakshmi et al. 2006) which also satisfies the IR spectral data for HA sample 1 where the elimination of $\mathrm{CO}_{3}{ }^{2-}$ peak has already been observed. 
Table II. Indexed $d$-spacings (in hexagonal unit cell) of XRD data obtained for synthesised HA sample 1

\begin{tabular}{|c|c|c|c|c|}
\hline \multicolumn{2}{|c|}{$d$-spacings $\left({ }^{\mathrm{O}} \mathrm{A}\right)$} & \multicolumn{2}{|c|}{ Intensity (\%) } & \multirow[t]{2}{*}{ (h $\mathrm{k}$ l) } \\
\hline Experimental & JCPDS & Experimental & JCPDS & \\
\hline 4.0748 & 4.0777 & 6.38 & 6.40 & 200 \\
\hline 3.8999 & 3.8885 & 4.45 & 5.80 & 111 \\
\hline 3.4395 & 3.4399 & 38.68 & 35.50 & $\begin{array}{lll}0 & 0 & 2\end{array}$ \\
\hline 3.1673 & 3.1695 & 8.36 & 8.50 & 102 \\
\hline 3.0861 & 3.0825 & 14.60 & 14.15 & 210 \\
\hline 2.8152 & 2.8131 & 100.00 & 100.00 & $\begin{array}{lll}2 & 1 & 1\end{array}$ \\
\hline 2.7744 & 2.7776 & 59.40 & 47.60 & 112 \\
\hline 2.7183 & 2.7185 & 55.42 & 64.20 & $\begin{array}{lll}3 & 0 & 0\end{array}$ \\
\hline 2.6296 & 2.6293 & 23.44 & 21.90 & 202 \\
\hline 2.5271 & 2.5282 & 5.30 & 4.00 & $\begin{array}{lll}3 & 0 & 1\end{array}$ \\
\hline 2.2619 & 2.2619 & 19.31 & 22.20 & 130 \\
\hline 2.1482 & 2.1487 & 5.28 & 5.50 & 131 \\
\hline 2.0610 & 2.0617 & 5.54 & 5.20 & 113 \\
\hline 1.9443 & 1.9428 & 28.19 & 27.60 & 222 \\
\hline 1.8914 & 1.8899 & 14.58 & 11.70 & 132 \\
\hline 1.8413 & 1.8399 & 32.19 & 30.30 & 213 \\
\hline 1.8060 & 1.8054 & 15.67 & 16.00 & 321 \\
\hline 1.7806 & 1.7797 & 11.83 & 11.00 & 140 \\
\hline 1.7538 & 1.7539 & 12.30 & 11.90 & 402 \\
\hline 1.7212 & 1.7199 & 15.73 & 13.70 & $\begin{array}{lll}0 & 0 & 4\end{array}$ \\
\hline 1.6447 & 1.6436 & 4.41 & 5.60 & 322 \\
\hline 1.4742 & 1.4738 & 6.99 & 7.40 & $\begin{array}{lll}5 & 0 & 2\end{array}$ \\
\hline
\end{tabular}

The crystallite sizes for HA sample 1 were calculated from Scherrer's relationship $\mathrm{D}=$ $79.5 / \Delta \cos \theta$, where $\mathrm{D}=$ crystal size $\left({ }^{\mathrm{O}} \mathrm{A}\right), \Delta$ $=$ FWHM in degree.

The Bragg reflection at (211), (112) and (300) planes of this sample were considered to calculate the crystallite size. The sizes of the crystallites for these phases are $41 \mathrm{~nm}$,
$65 \mathrm{~nm}$ and $34 \mathrm{~nm}$ respectively. The lattice parameters of this HA sample 1 were measured as $\mathrm{a}=\mathrm{b}=9.4164{ }^{\mathrm{O}} \mathrm{A}$ and $\mathrm{c}=6.8789^{\circ} \mathrm{A}$ which are very close to those values obtained from the JCPDS (ref. code: 89-6439) standard data $\left(\mathrm{a}=\mathrm{b}=9.4172{ }^{\circ} \mathrm{A}\right.$ and $\mathrm{c}=6.8799$ $\left.{ }^{\circ} \mathrm{A}\right)$ and the lattice parameters of human bones $\left(\mathrm{a}=\mathrm{b}=9.419{ }^{\mathrm{O}} \mathrm{A}\right.$ and $\left.\mathrm{c}=6.88^{\mathrm{O}} \mathrm{A}\right)$ 
(LeGeros et al. 1993). This good agreement between the experimental data and standard values reflects that the synthesized HAP sample resembles the feature of pure and single apatite phase having hexagonal structure. The formation of apatite of single phase also confirmed the $\mathrm{Ca} / \mathrm{P}$ molar ratio 1.66 which is very close to that of crystalline apatite (Elliot et al. 1994, Xu et al. 2001).

Since sintering temperature or calcination effect plays an important role in the formation of crystallite phase (Feng et al. 2005), the XRD profile of the as received HA
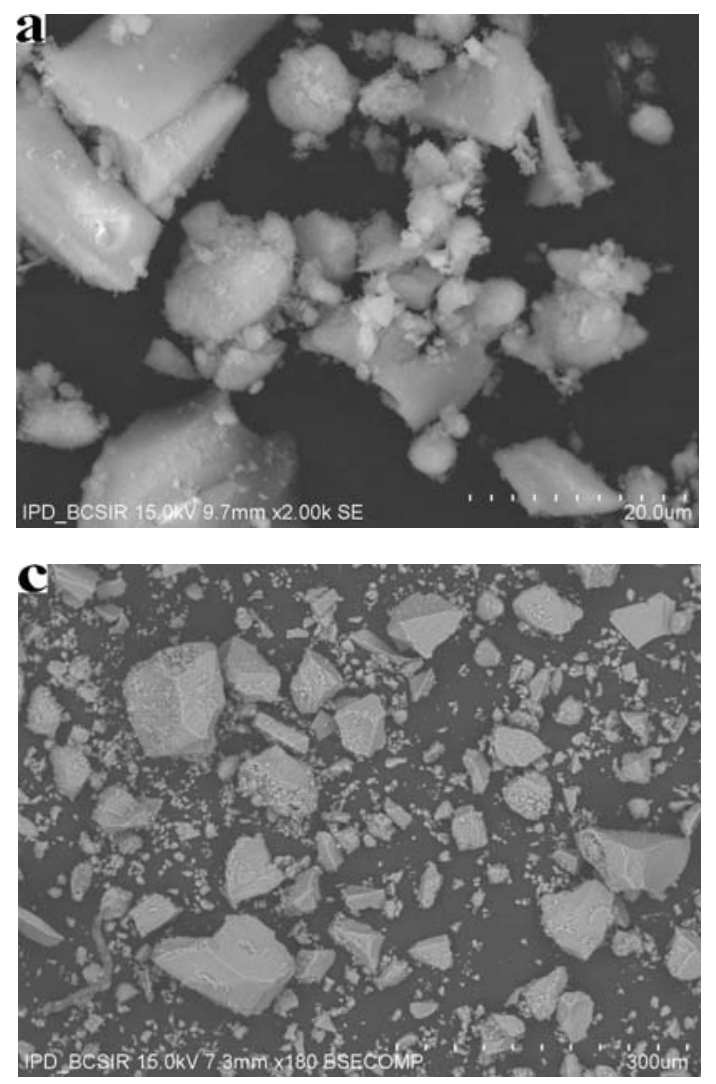

sample (i.e. after oven dried at $110^{\circ} \mathrm{C}$ ) was recorded and displayed in Figure 4b. Although the formation of hydroxyapatite was confirmed by comparing the experimental data with the JCPDS standard file (ref. code: 89-6439), but it is cleared from the XRD pattern that the HA sample under investigation has formed in poorly crystalline phase together with amorphous phase supporting the IR informations. This behaviour can be attributed to the temperature effect, since this sample 2 remained in only oven dried state. It is well established that the increasing of sintering temperature
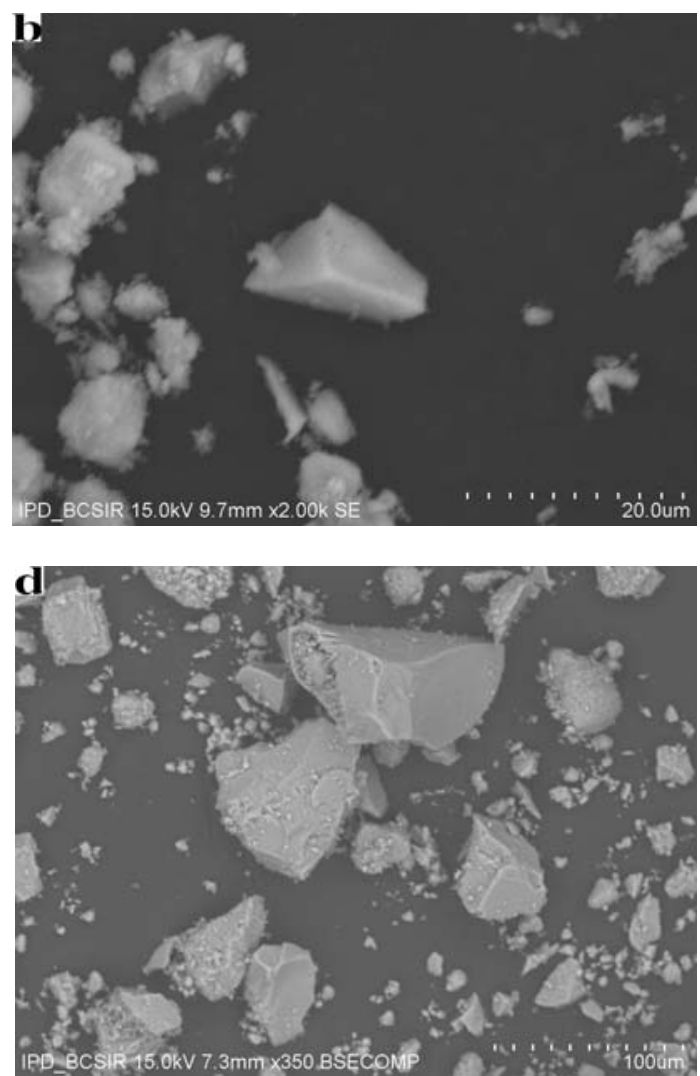

Figure 5. SEM micrographs of synthesised HA sample 1 (a and b) magnification 2000 (c) magnification 180 and (d) magnification 350. 
increases the crystallite degree resulting several distinct peaks for HA (Feng et al. 2005). So the low crystallinity and amorphous nature can be upgraded or improved to a solid, crystalline phase via the thermal treatment (Santos et al. 2004).

The morphology and micro structural features of the HA samples (both 1 and 2) recorded at different magnifications are shown in SEM micrographs. The micrographs (Fig. 5a - 5d) representing the
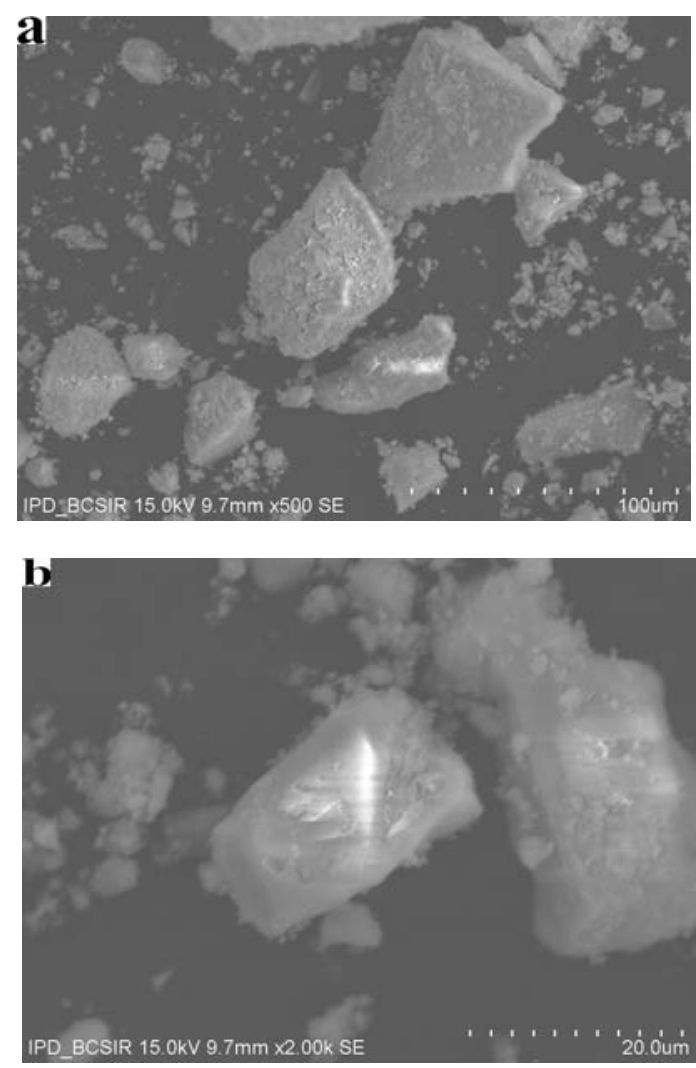

Fig.6. SEM micrographs of synthesised HA sample 2 (a) magnification 500 (b) magnification 2000. micro structural features of HA sample 1, exhibit a combination of spherical, hexagonal and cylindrical shapes having crystal size of $~ 30$ - $60 \mathrm{~nm}$. On the other hand, the different magnified micrographs of HA sample 2 (Fig. 6a - 6b) does not shows clear crystallite phases since the sample was a combination of amorphous and crystallite phase.

\section{Conclusions}

Ca-hydroxyapatite nano powders have been successfully synthesised using calcined and uncalcined egg shell as the prime source of Ca. The results showed that HA sample 1 consists of single crystallite apatite phase and sample 2 contains both amorphous and crystalline phase. The crystallinity of this later sample can be improved by further sintering of the product. However, the egg shell derivated HA will no doubt be a cost-effective bioceramic material for biomedical applications. Additionally, utilisation of egg shell will be an effective material-recycling technology for waste management.

\section{Acknowledgement}

We thank Dr. Dilip Kumar Saha of Atomic Energy Commission for XRD, Mr. Fariduddin Farhad and Mr. Shudhangsu Kumar of BCSIR for SEM and FT-IR respectively. Financial support from IGCRT, BCSIR is gratefully acknowledged. 


\section{References}

Balázsi, C. Wéber, F. Kövér, Z. Horváth, E. Némth, C. (2007) Preparation of calciumphosphate bioceramics from natural resources, J. Euro. Ceram. Soc. 27: 1601.

Elliot, J.C. (1994) Structure and Chemistry of The Apatites and The Other Calcium Orthophosphates (Elsevier Science, Amsterdam).

Feng, W. Mu-sen, L. Yu-peng, L. Yong-xin, Q. (2005) A simple sol-gel technique for preparing hydroxyapatite nanopowders, Mater. Lett. 59: 916.

Mahabole, M.P. Aiyer, R.C. Ramakrishna, CV. Sreedhar B., Khairnar RS., (2005) Synthesis, characterization and gas sensing property of hydroxyapatite ceramic, Bull. Mater. Sci., 28(6): 535.

LeGeros, R.Z. Calcium Phosphate in Oral Biology and Medicine, Karger: Basel, Switzerland, 1991.

LeGeros, R.Z., LeGeros, J.P. (1993) Dense Hydroxyapatite, In: Hench LL, Wilson J, editors. An introduction to bioceramics. London: World Scientific Publishing Co, 144.

Markovic, M. Fowler, B.O. Tung, M.S. (2004) Preparation and Comprehensive Characterization of a Calcium Hydroxy apatite Reference Material, J. Res. Natl. Inst. Stand. Technol., 109(6): 553.
Prabakaran, K. Balamurugan, A. Rajeswari, S. (2005) Development of calcium phosphate based apatite from hen's eggshell Bull. Mater. Sci., 28(2): 115.

Santos, M.H. Oliveira, M de. Souza LPdeF., Mansur, H.S. Vasconcelos. W.L.(2004) Synthesis Control and Characterization of Hydroxyapatite prepared by wet precipitation process, Materials Research, 7(4): 625.

Sasikumar, S. Vijayaraghavan, R. (2006) Low Temperature Synthesis of Nanocrystalline Hydroxyapatite from Egg Shells by Combustion Method, Trends Biomater. Artif. Organs, 19(2): 70.

Thamaraiselvi, T.V. Prabakaran, K. Rajeswari, S. (2006) Synthesis of Hydroxyapatite that Mimic Bone Minerology, Trends Biomater. Artif. Organs, 19(2): 81.

Tas, A.C. (2000) Synthesis of biomimetic Cahydroxyapatite powders at $37^{\circ} \mathrm{C}$ in synthetic body fluids, Biomaterials, 21: 1429.

Vijayalakshmi, U. Rajeswari, S. (2006) Preparation and Characterization of Microcrystalline Hydroxyapatite Using Sol Gel Method, Trends Biomater. Artif. Organs, 19(2): 57.

Xu, G. Aksay, I.A. Groves, J.T. (2001) Continuous Crystalline Carbonate Apatite Thin Films. A Biomimetic Approach, J. Am. Chem. Soc., 123: 2196.

Received : July 02, 2008;

Accepted : August 21, 2008 